\title{
Adaptação e validação de uma escala de atitudes em relação a frações ${ }^{1}$
}

\author{
Andresa Maria Justulin \\ Doutoranda em Educação Matemática, UNESP/Rio Claro \\ andresa_justulin@yahoo.com.br \\ Nelson Antonio Pirola \\ Professor, Faculdade de Ciências, UNESP/Bauru \\ npirola@uol.com.br
}

\section{Resumo}

O presente estudo refere-se à adaptação e validação de uma escala de atitudes em relação a frações. O instrumento elaborado baseou-se na escala de atitudes em relação à matemática, testada, adaptada e validada por Brito (1996). Os sujeitos foram 373 estudantes do Ensino Médio de uma escola estadual da região de Jaú, SP. Além da escala de atitudes, os alunos responderam a um questionário sobre a vida escolar e sobre a Matemática e as atividades desenvolvidas na disciplina. Os vinte itens da escala foram submetidos à análise fatorial e os resultados obtidos mostraram que a adequação da amostra, medida pelo teste de Kaiser-Meyer-Oklin, KMO = 0,958, é considerada excelente, pois está acima de 0,900. Já o coeficiente de alfa de Cronbach que varia de 0 a 1 , foi de 0,9443 , o que demonstra uma boa consistência interna do instrumento.

Palavras chave: escala de atitudes; frações; matemática; atitudes; psicologia.

\begin{abstract}
This study refers to the adaptation and validation of a scale of attitudes towards fractions. The instrument developed was based on the scale of attitudes toward mathematics, tested, adapted and validated by Brito (1996). The subjects were 373 high school students of a public school in the region of Jau, Brazil. Besides the attitude scale, students answered a questionnaire about school life and about Mathematics and the activities conducted in the discipline. The twenty scale items were subjected to factor analysis and the results showed that the adequacy of the sample, measured by the test of Kaiser-Meyer-Oklin, $\mathrm{KMO}=0.958$, is considered excellent because it is above 0.900 . Already coefficient Cronbach's alpha ranging from 0 to 1 , was 0.9443 , which indicates a good internal consistency.
\end{abstract}

Keywords: attitude scale; fractions; mathematics; attitudes; psychology.

\footnotetext{
${ }^{1}$ Boletim Gepem (Online) ISSN: 2176-2988 | n. 64 - Jan./Jun. 2014 (texto em diagramação).
} 


\section{Atitudes em relação à Matemática}

Este trabalho faz parte da dissertação de mestrado da primeira autora e teve como objetivo a validação de um instrumento para avaliar as atitudes dos alunos em relação a um conteúdo específico da matemática escolar, as frações. A escolha desse conteúdo deu-se após a observação de resultados dos estudantes no $\mathrm{SARESP}^{2}$ em questões envolvendo os números racionais e nas experiências da autora como docente no Ensino Básico.

No que se refere às atitudes em relação à matemática, o Grupo de Pesquisa sobre Psicologia da Educação Matemática (PSIEM) da Faculdade de Educação da Universidade Estadual de Campinas (UNICAMP) apresenta um grande número de trabalhos realizados. As linhas de pesquisa do grupo são: atitudes, gênero e matemática, habilidades, solução de problemas e formação de conceitos.

Brito, coordenadora do PSIEM, em sua tese de Livre Docência (1996), realizou um amplo estudo sobre as atitudes em relação à Matemática e mostrou que a literatura especializada envolvendo este tema traz definições diferentes para o conceito de atitudes, variando de acordo com o autor e a época.

Klausmeier E Goodwin (1977) afirmaram que a atitude seria um conceito que pode ser definido, e, portanto, visto tanto como um constructo mental quanto como uma entidade pública. Para os autores, entidade pública é entendida como a informação organizada que corresponde aos significados presentes em dicionários, enciclopédias e em outros livros. Por outro lado, o conceito como constructo mental é idiossincrático, refere-se à informação acumulada pelo indivíduo ao longo de sua vida, de acordo com experiências de aprendizagem e pelo seu próprio desenvolvimento. Assim, a atitude possui atributos relevantes e irrelevantes como todos os conceitos. Para os referidos autores,

A palavra atitude é usada para designar tanto disposições emocionais matizadas de indivíduos, como também entidades públicas identificáveis, que são usadas para comunicar significados entre indivíduos que falam a mesma língua. Assim, consideramos a atitude como tendo um referente individual e um público (p. 413).

\footnotetext{
${ }^{2}$ SARESP- Sistema de Avaliação do Rendimento Escolar do Estado de São Paulo
} 
Outros autores, como Bloom ${ }^{3}$ (1974) citado por Brito (1996), definem atitudes como uma disposição do indivíduo para "olhar" algo de maneira positiva ou negativa. O autor afirma que as experiências de sucesso e fracasso na escola levam ao desenvolvimento de atitudes negativas ou positivas.

Nesta pesquisa, atitude será entendida como:

\begin{abstract}
Uma disposição pessoal, idiossincrática, presente em todos os indivíduos, dirigida a objetos, eventos ou pessoas, que assume diferente direção e intensidade de acordo com as experiências do indivíduo. Além disso, apresenta componentes de domínio afetivo, cognitivo e motor (BRITO, 1996, p.11).
\end{abstract}

As atitudes não são gerais e possuem sempre um referente, ou seja, é sempre "atitude em relação a" e, sendo um evento interno, aprendido, com componentes cognitivos e afetivos que variam em intensidade, é dirigida a um objeto específico.

A formação de atitudes positivas para qualquer disciplina parece motivar o estudante, fazendo com que o mesmo se interesse pelos conteúdos tratados. Para Sarabia (1998), "as atitudes guiam os processos perceptivos e cognitivos que conduzem à aprendizagem de qualquer tipo de conteúdo educacional seja conceitual, procedimental ou atitudinal” (p.136).

Krutetskii (1976) e Klausmeier e Goodwin (1977) afirmaram que as atitudes são uma espécie de "condição necessária" para que o indivíduo tenha um bom aproveitamento na realização de uma tarefa. Os últimos autores indicaram que, se um indivíduo possui uma atitude favorável em relação a alguma coisa, procurará se aproximar dela e irá defendê-la, enquanto aquele que tem uma atitude desfavorável irá evitá-la (p.417).

\title{
Escalas de atitudes em relação à Matemática
}

Existem vários métodos que permitem o estudo e a compreensão das atitudes. As técnicas mais comuns para se acessarem as atitudes são:

\footnotetext{
${ }^{3}$ BLOOM, B.S. The Taxonomy of Educational Objectives: Affective and Cognitive Domains. New York: David McKay, 1974.
} 
... escalas diferenciais (Thurstone), escala de pontos ou classificações (Rating Scales), escalas de classificação somativa, escalas de diferencial semântico, inventários de interesse, hierarquia de preferências ou 'ranking', técnicas projetivas, observação antropológica, entrevistas, dados observacionais controlados, análise de conteúdo de depoimentos, etc... (BRITO, 1996, p.31).

Aiken e Dreger (1961) e Aiken (1963, 1970) contribuíram intensamente para o estudo das atitudes. Desde o final da primeira metade da década de setenta, os trabalhos de Aiken aparecem citados em praticamente todos os estudos sobre atitudes em relação à Matemática e Ciências. Os estudos desses autores envolvem desde a construção de escalas de atitudes até a investigação sobre a influência das atitudes no desempenho dos alunos.

Algumas escalas de atitudes em relação à matemática tratam o fenômeno como um componente (gostar) em relação ao seu oposto (não gostar). Essas são escalas unidimensionais, de acordo com Aiken (1963) e Dutton ${ }^{4}$ (1954), e não incluem sentimentos com relação aos componentes e razões da escolha de uma alternativa.

As escalas multidimensionais buscam verificar a existência e intensidade das atitudes em relação à Matemática, através dos seus vários componentes. Incluem proposições referentes ao método, aos professores, à solução de problemas, dificultando a manifestação clara do sentimento com relação a uma dimensão específica. De acordo com Brito (1996), a atitude é um afeto enquanto "disposição do indivíduo em relação a" e assume aspecto multidimensional quando se volta para um objeto, evento ou coisa, porque essas situações apresentam inúmeros componentes.

A Matemática é uma disciplina complexa e envolve uma diversidade de conteúdos. O educando, certamente, apresenta sentimentos diferentes com relação a eles, podendo gostar de geometria, mas sentir aversão à álgebra ou aos cálculos longos. São encontrados, entretanto, de acordo com Aiken $(1963,1970)$, estudos sobre as atitudes com relação a conteúdos específicos ou a alguns tipos de problemas matemáticos.

É possível elaborar escalas compostas de proposições mais gerais e, assim, medir o sentimento com relação à disciplina como um todo. O sujeito exprimirá o resultado de suas experiências matemáticas de maneira geral, isso porque, se algum aspecto particular da disciplina

\footnotetext{
${ }^{4}$ DUTTON, W. H. Attitudes of Junior High School Pupils Toward Arithmetic. School Review, n. 64, p.18-22, 1956.
} 
(por exemplo, a álgebra) for muito aversivo, certamente será generalizado, passando o aluno a não gostar da disciplina como um todo.

\section{Procedimentos utilizados para adaptação e validação da escala de Atitudes em relação a frações}

A escala de atitudes em relação a frações foi adaptada da escala de atitudes em relação à matemática de Brito (1996). Inicialmente, foi realizado um estudo piloto com um grupo de 95 alunos de uma escola pública com o objetivo de verificar se os alunos compreendiam o significado de cada item da escala. Esse estudo piloto, aplicado a uma pequena amostra de alunos, buscou averiguar se os participantes desconheciam o significado de alguma palavra ou, ainda, se alguma afirmação estava gerando dúvidas ou não estava sendo compreendida por eles. Juntamente com a escala foi aplicado um questionário composto por 15 (quinze) questões, adaptado do questionário proposto por Brito (1996). Esse questionário buscou conhecer o perfil dos participantes e as perguntas versavam sobre a idade, série, gênero, se o aluno havia sido reprovado anteriormente e sobre as preferências do participante em relação às disciplinas escolares. Não serão apresentados os dados desse questionário, neste artigo, em razão dos objetivos do mesmo. Maiores detalhes sobre o perfil dos sujeitos podem ser obtidos na dissertação de Justulin (2009).

A escala de atitudes em relação à fração adaptada para este trabalho é do tipo likert, de quatro pontos e composta por 21 questões. Dez proposições referem-se às atitudes negativas e dez às atitudes positivas. A pontuação máxima da escala é 80 pontos.

\section{Sujeitos}

Para validar a escala de atitudes em relação à fração e com o objetivo de analisar possíveis correlações entre as diversas variáveis envolvidas nesse estudo, utilizou-se o software estatístico SPSS $^{5}$. Para a validação da escala participaram 373 sujeitos, considerando-se os sujeitos participantes de todas as etapas da pesquisa.

\footnotetext{
${ }^{5}$ Statistical Package for Social Sciences - Pacote Estatístico para Ciências Sociais
} 


\section{Escala de Atitudes em relação à Fração}

Com o objetivo de verificar as atitudes dos alunos em relação a frações com ênfase na solução de problemas envolvendo esse conteúdo, foi adaptada uma escala com base nos trabalhos de Brito (1996). Essa é uma escala do tipo likert que apresenta as opções Concordo totalmente, Concordo, Discordo totalmente e Discordo, cuja pontuação varia de 20 a 80 pontos. Para as proposições que se referiam às atitudes positivas foram atribuídas as seguintes pontuações: Concordo Totalmente - 4 pontos, Concordo - 3 pontos, Discordo - 2 pontos e Discordo Totalmente - 1 ponto.

As proposições que avaliaram atitudes positivas foram:

03- Eu acho "frações" muito interessante e gosto das aulas sobre isso.

04- Frações é um conceito fascinante e divertido.

05- Problemas com frações me fazem sentir seguro(a) e são, ao mesmo tempo, estimulante.

09- O sentimento que tenho com relação a Frações é bom.

11- "Frações" é um conteúdo que eu aprecio grandemente.

14- Eu gosto realmente de frações.

15- "Frações" é um dos conteúdos que eu realmente gosto de estudar na escola.

18- Eu fico mais feliz em aulas sobre frações que em aulas de qualquer outro conteúdo.

19- Eu me sinto tranquilo(a) quando soluciono problemas sobre frações e gosto muito desse conteúdo.

20- Eu tenho uma reação definitivamente positiva com relação a frações: Eu gosto e aprecio problemas com esse conteúdo.

As demais afirmações verificaram as atitudes negativas dos estudantes em relação à fração. A pontuação atribuída foi: Discordo Totalmente - 4 pontos, Discordo - 3 pontos, Concordo - 2 pontos e Concordo Totalmente - 1 ponto. Também foram dez as proposições que se referiam às atitudes negativas:

01- Eu fico sempre sob uma terrível tensão quando resolvo problemas que envolvem frações.

02- Eu não gosto de frações e me assusta ter que trabalhar esse conceito.

06- "Dá um branco" na minha cabeça e não consigo pensar claramente quando resolvo problemas com frações.

07- Eu tenho sensação de insegurança quando me esforço para resolver problemas de frações. 
08- Conteúdos com frações me deixam inquieto(a), descontente, irritado(a) e impaciente.

10- Problemas com frações me fazem sentir como se estivesse perdido(a) em uma selva de números e sem encontrar a saída.

12- Quando ouço a palavra Fração, eu tenho um sentimento de aversão.

13- Eu encaro problemas sobre frações com um sentimento de indecisão, que é resultado do medo de não ser capaz de solucionar problemas.

16- Pensar sobre a obrigação de resolver um problema com frações me deixa nervoso(a).

17- Eu nunca gostei de solucionar problemas sobre frações, e esse é o conteúdo que me dá mais medo.

A proposição 21 - "Não tenho um bom desempenho para solucionar problemas sobre frações" - avaliou a autopercepção do aluno quanto ao seu desempenho em frações e atividades relacionadas a esse conceito.

\section{Validação da escala de Atitudes em relação a frações}

Inicialmente, realizou-se uma análise descritiva dos resultados obtidos a partir das respostas de 373 sujeitos à escala de atitudes em relação a frações. A tabela 1 mostra a análise descritiva das proposições, cuja média varia de 1,72 a 2,60, indicando uma tendência às atitudes negativas. Quanto à pontuação da escala, valores das proposições tomam valores 1 (um), se forem muito negativas, e 4 (quatro), se forem muito positivas. A menor média encontrada foi na proposição A18, "Eu fico mais feliz em aulas sobre frações que em aulas de qualquer outro conteúdo", o que pode ser justificado pela tendência a atitudes negativas em relação a esse conteúdo.

Em seguida, buscando-se analisar a validade convergente do instrumento - a escala de atitudes em relação a frações - realizou-se uma análise fatorial. Por meio é possível identificar e avaliar um grupo de fatores e representar as relações entre as variáveis. Na escala em questão, as variáveis consideradas foram os vinte itens e a análise fatorial permite garantir que o instrumento é adequado para medir aquilo que se propõe.

Para isso, em primeiro lugar, ao se analisarem as correlações das proposições, verifica-se a possibilidade da utilização da análise fatorial, pois esse é um dos pressupostos dessa técnica estatística. Para isso foi utilizado o teste de esfericidade de Bartlett, que, segundo Pereira (1999), 
testa a hipótese de que a matriz de correlação é a matriz identidade, isto é, que não há correlação entre as proposições. O valor qui-quadrado aproximado foi de 4759,038 com p =0,000, o que permite concluir que a matriz de correlação é apropriada para utilizar esta técnica multivariada.

O outro pressuposto é a adequação da amostra, medida pelo teste de Kaiser-Meyer-Oklin, $\mathrm{KMO}=0,958$, considerado excelente, pois está acima de 0,900 (Ibid, 1999).

Com esses dois pressupostos validados, foi utilizado o modelo fatorial dos componentes principais, que permite resumir a maioria das informações originais (variâncias) em um número finito de fatores. Além disso, foi utilizada a rotação Varimax, que, conforme Sharma ${ }^{6}$ (1996) citado por Silva (2000) é uma operação que possibilita obter a estrutura fatorial na qual cada variável tende a carregar altamente em um só fator.

Para extrair os fatores de um conjunto de variáveis, existem dois critérios, o primeiro é que os autovalores sejam maiores que um, e o segundo é que sejam os fatores que respondem pela maior variância obtida. A Tabela 1 mostra esses dados.

Tabela 1 - Estatísticas das proposições da escala e resultados da análise fatorial

\begin{tabular}{|c|c|c|c|c|c|c|c|}
\hline \multicolumn{4}{|c|}{ Análise descritiva } & \multicolumn{4}{|c|}{ Análise fatorial } \\
\hline \multirow[t]{2}{*}{ Proposições } & \multirow{2}{*}{$\begin{array}{c}\mathrm{N}^{\mathrm{o}} \mathrm{de} \\
\text { sujeitos }\end{array}$} & \multirow[t]{2}{*}{ Média } & \multirow{2}{*}{$\begin{array}{l}\text { Desvio } \\
\text { padrão }\end{array}$} & \multirow[t]{2}{*}{ Fator } & \multirow[t]{2}{*}{ Autovalor } & \multicolumn{2}{|c|}{ variância total explicada } \\
\hline & & & & & & $\%$ & $\%$ acumulada \\
\hline A1 & 373 & 2,46 & 0,81 & 1 & 9,868 & 49,342 & 49,342 \\
\hline $\mathrm{A} 2$ & 373 & 2,49 & 0,82 & 2 & 2,184 & 10,921 & 60,263 \\
\hline A3 & 373 & 2,22 & 0,75 & 3 & 0,875 & 4,375 & 64,639 \\
\hline A4 & 373 & 1,96 & 0,69 & 4 & 0,763 & 3,813 & 68,452 \\
\hline A5 & 373 & 1,97 & 0,66 & 5 & 0,628 & 3,141 & 71,593 \\
\hline A6 & 373 & 2,34 & 0,81 & 6 & 0,564 & 2,820 & 74,413 \\
\hline A7 & 373 & 2,40 & 0,74 & 7 & 0,547 & 2,735 & 77,148 \\
\hline A8 & 373 & 2,45 & 0,85 & 8 & 0,511 & 2,555 & 79,703 \\
\hline A9 & 373 & 2,19 & 0,67 & 9 & 0,471 & 2,353 & 82,056 \\
\hline A10 & 373 & 2,60 & 0,84 & 10 & 0,448 & 2,242 & 84,298 \\
\hline A11 & 373 & 2,00 & 0,68 & 11 & 0,412 & 2,062 & 86,360 \\
\hline A12 & 373 & 2,55 & 0,74 & 12 & 0,399 & 1,996 & 88,355 \\
\hline A13 & 373 & 2,47 & 0,76 & 13 & 0,386 & 1,932 & 90,288 \\
\hline A14 & 373 & 1,94 & 0,72 & 14 & 0,334 & 1,672 & 91,959 \\
\hline A15 & 373 & 1,92 & 0,69 & 15 & 0,326 & 1,628 & 93,588 \\
\hline A16 & 373 & 2,46 & 0,72 & 16 & 0,299 & 1,495 & 95,083 \\
\hline A17 & 373 & 2,63 & 0,79 & 17 & 0,286 & 1,430 & 96,513 \\
\hline A18 & 373 & 1,73 & 0,62 & 18 & 0,278 & 1,389 & 97,901 \\
\hline A19 & 373 & 2,00 & 0,68 & 19 & 0,239 & 1,194 & 99,095 \\
\hline A20 & 373 & 1,99 & 0,67 & 20 & 0,181 & 0,905 & 100,000 \\
\hline
\end{tabular}

Fonte: Dados da pesquisa

\footnotetext{
${ }^{6}$ SHARMA, S. Applied multivariate techniques. New York: John Wiley \& Sons, 1996, 493p.
} 
Os fatores 1 e 2 explicam 60,3\% da variância total, sendo que o primeiro respondeu por $49,3 \%$ e o segundo por $10,9 \%$. Os outros autovalores respondem por menos do que $5 \%$ da variância, portanto foram descartados. A decisão por admitir os dois fatores é reforçada pelo critério do valor dos autovalores que devem ser maiores do que um, como ilustrado pelo "screeplot", na Figura 1.

Figura 1- Gráfico dos autovalores (screeplot)

\section{Scree Plot}

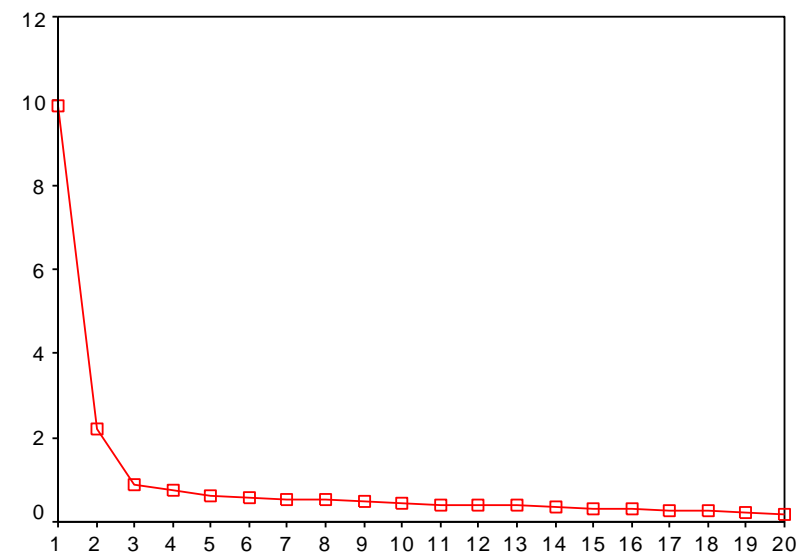

Component Number

Fonte: Dados da pesquisa

A Tabela 2 mostra as cargas fatoriais de cada proposição e a Figura 2 ilustra a distribuição espacial das proposições, que permite concluir a presença da unidimensionalidade da escala, que tem dois pólos opostos, as proposições negativas e as positivas, que são classificadas perfeitamente em dois grupos.

Tabela 2 - Matriz dos componentes fatoriais, inicial e com rotação Varimax ${ }^{7}$, da escala de atitudes em relação a frações

\begin{tabular}{c|c|c|c|c|c}
\hline \multirow{2}{*}{ Natureza } & \multirow{2}{*}{ Proposição } & \multicolumn{2}{|c|}{ Inicial } & \multicolumn{2}{c}{ Rotação Varimax } \\
\cline { 3 - 6 } & & Fator 1 & Fator 2 & Fator 1 & Fator 2 \\
\hline \multirow{2}{*}{ N } & A1 & 0,593 & 0,364 & 0,181 & 0,672
\end{tabular}

\footnotetext{
${ }^{7}$ É um método de rotação ortogonal e pretende que, para cada componente principal, existam apenas alguns pesos significativos e todos os outros sejam próximos de zero.
} 


\begin{tabular}{llllll} 
N & A2 & 0,746 & 0,164 & 0,429 & 0,632 \\
P & A3 & 0,763 & $-0,306$ & 0,764 & 0,302 \\
P & A4 & 0,687 & $-0,403$ & 0,776 & 0,180 \\
P & A5 & 0,648 & $-0,274$ & 0,659 & 0,246 \\
N & A6 & 0,657 & 0,435 & 0,178 & 0,767 \\
N & $\mathbf{A 7}$ & 0,617 & 0,496 & 0,107 & 0,784 \\
N & $\mathbf{A 8}$ & 0,766 & 0,227 & 0,401 & 0,691 \\
P & $\mathbf{A 9}$ & 0,762 & $-0,175$ & 0,674 & 0,397 \\
N & $\mathbf{A 1 0}$ & 0,661 & 0,311 & 0,266 & 0,680 \\
P & $\mathbf{A 1 1}$ & 0,700 & $-0,305$ & 0,718 & 0,260 \\
N & $\mathbf{A 1 2}$ & 0,661 & 0,223 & 0,327 & 0,616 \\
N & $\mathbf{A 1 3}$ & 0,663 & 0,383 & 0,218 & 0,734 \\
P & $\mathbf{A 1 4}$ & 0,801 & $-0,321$ & 0,802 & 0,318 \\
P & $\mathbf{A 1 5}$ & 0,786 & $-0,349$ & 0,811 & 0,287 \\
N & $\mathbf{A 1 6}$ & 0,745 & 0,367 & 0,289 & 0,779 \\
N & $\mathbf{A 1 7}$ & 0,700 & 0,324 & 0,286 & 0,716 \\
P & $\mathbf{A 1 8}$ & 0,509 & $-0,384$ & 0,634 & 0,07 \\
P & $\mathbf{A 1 9}$ & 0,759 & $-0,263$ & 0,732 & 0,331 \\
P & $\mathbf{A 2 0}$ & 0,750 & $-0,333$ & 0,774 & 0,274 \\
\hline & & & & &
\end{tabular}

Fonte: Dados da pesquisa

Figura 2 - Gráfico de dispersão das proposições da escala de atitudes em relação a Frações segundo as cargas fatoriais

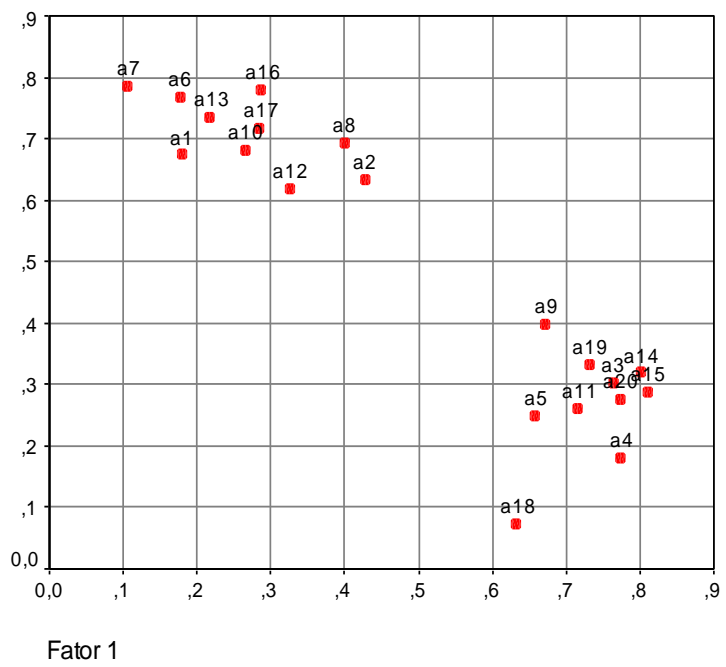

Fonte: Dados da pesquisa 
Nota-se na figura 2 que as proposições, a partir de suas cargas fatoriais, estão concentradas em dois polos opostos que representam as atitudes negativas e as atitudes positivas.

\section{Análise de confiabilidade da escala}

Dando prosseguimento à análise da validade da escala, analisou-se a consistência interna dos itens do instrumento. Dessa forma, pode-se garantir que os itens da escala inter-relacionamse. Para isso, determinou-se o coeficiente Alfa de Cronbach ${ }^{8}$.

O coeficiente de alfa de Cronbach foi de 0,9443, que é considerado muito bom. Brito (1998) afirmou que, em seus estudos, a maioria dos autores que trabalharam com escalas de atitudes sugere o valor de 0,80 como o mínimo aceitável. Além disso, esse coeficiente varia de 0,9400 a 0,9445 quando uma proposição é deletada (Tabela 3), ou seja, quase nenhuma variação é observada, indicando que todos os itens são igualmente importantes na formação da escala.

Tabela 3 - Distribuição dos coeficientes Alfa de Cronbach da escala de atitudes em relação a frações, quando a proposição foi deletada

\begin{tabular}{ccccc}
\hline Proposição & $\begin{array}{c}\text { Média da escala se a } \\
\text { proposição for deletada }\end{array}$ & $\begin{array}{c}\text { Variância da escala } \\
\text { se a proposição for } \\
\text { deletada }\end{array}$ & $\begin{array}{c}\text { Correlação item } \\
\text { corrigido }- \text { total }\end{array}$ & $\begin{array}{c}\text { Alfa de Cronbach } \\
\text { se a proposição for } \\
\text { deletada }\end{array}$ \\
\hline A1 & 42,3029 & 96,4644 & 0,5616 & 0,9433 \\
A2 & 42,2654 & 94,0396 & 0,7153 & 0,9406 \\
A3 & 42,5416 & 94,9909 & 0,7150 & 0,9406 \\
A4 & 42,7962 & 97,0068 & 0,6307 & 0,9420 \\
A5 & 42,7936 & 97,8793 & 0,5965 & 0,9425 \\
A6 & 42,4236 & 95,3846 & 0,6321 & 0,9421 \\
A7 & 42,3566 & 96,8967 & 0,5918 & 0,9426 \\
A8 & 42,3083 & 93,1708 & 0,7394 & 0,9402 \\
A9 & 42,5710 & 96,1757 & 0,7187 & 0,9407 \\
A10 & 42,1555 & 95,0456 & 0,6286 & 0,9422 \\
A11 & 42,7560 & 96,9699 & 0,6467 & 0,9418 \\
A12 & 42,2064 & 96,3632 & 0,6258 & 0,9421 \\
A13 & 42,2895 & 96,0719 & 0,6353 & 0,9419 \\
A14 & 42,8177 & 95,0258 & 0,7541 & 0,9400 \\
A15 & 42,8391 & 95,6676 & 0,7385 & 0,9404 \\
A16 & 42,3003 & 95,3666 & 0,7244 & 0,9405 \\
A17 & 42,1287 & 95,0855 & 0,6709 & 0,9414 \\
A18 & 43,0322 & 100,0366 & 0,4531 & 0,9445 \\
A19 & 42,7587 & 96,0492 & 0,7123 & 0,9408 \\
A20 & 42,7721 & 96,3969 & 0,7009 & 0,9410 \\
\hline
\end{tabular}

Fonte: Dados da pesquisa

${ }^{8} \mathrm{O}$ coeficiente $\alpha$ de Cronbach estima a confiabilidade interna de um questionário que se aplica em uma pesquisa. Como os itens de um questionário utilizam a mesma escala de medição, o coeficiente tem valor de 0 a 1. 


\section{Análise das atitudes em relação a frações}

As atitudes parecem se formar, principalmente, pela negação de sentimentos negativos, do que pela afirmação de sentimentos positivos. Na tabela 4 percebe-se a discordância dos sujeitos em todas as proposições negativas, com exceção da afirmação 17, "Eu nunca gostei de solucionar problemas sobre frações e esse é o conteúdo que me dá mais medo”.

Tabela $4^{9}$ - Distribuição da porcentagem dos sujeitos nas proposições da escala de atitudes em relação a frações

\begin{tabular}{|c|c|c|c|c|c|c|}
\hline Natureza & Proposição & $\mathrm{CT}$ & $\mathrm{C}$ & $\mathrm{D}$ & DT & Total \\
\hline Negativa & $\begin{array}{l}\text { A1- Eu fico sempre sob uma terrível tensão quando resolvo } \\
\text { problemas que envolvem frações }\end{array}$ & 10,4 & 35,2 & 44,3 & 10,1 & 100,0 \\
\hline Negativa & $\begin{array}{l}\text { A2- Eu não gosto de frações e me assusta ter que trabalhar esse } \\
\text { assunto }\end{array}$ & 10,7 & 38,0 & 41,2 & 10,2 & 100,0 \\
\hline Positiva & $\begin{array}{l}\text { A3 - Eu acho "frações" muito interessante e gosto das aulas sobre } \\
\text { isso. }\end{array}$ & 16,0 & 50,7 & 29,3 & 4,0 & 100,0 \\
\hline Positiva & A4 - Frações é um conceito fascinante e divertido. & 24,8 & 55,5 & 18,7 & 1,1 & 100,0 \\
\hline Positiva & $\begin{array}{l}\text { A5 - Problemas com frações me fazem sentir seguro (a) e é, ao } \\
\text { mesmo tempo, estimulante. }\end{array}$ & 21,3 & 63,2 & 13,3 & 2,1 & 100,0 \\
\hline Negativa & $\begin{array}{l}\text { A6- "Dá um branco" na minha cabeça e não consigo pensar } \\
\text { claramente quando resolvo problemas com frações. }\end{array}$ & 7,7 & 32,5 & 45,6 & 14,1 & 100,0 \\
\hline Negativa & $\begin{array}{l}\text { A7 - Eu tenho sensação de insegurança quando me esforço para } \\
\text { resolver problemas de frações. }\end{array}$ & 7,2 & 34,4 & 50,1 & 8,3 & 100,0 \\
\hline Negativa & $\begin{array}{l}\text { A8 - Conteúdos com frações me deixam inquieto (a), descontente, } \\
\text { irritado (a) e impaciente. }\end{array}$ & 12,0 & 33,3 & 42,7 & 12,0 & 100,0 \\
\hline Positiva & A9 - O sentimento que tenho com relação a Frações é bom. & 13,9 & 54,9 & 30,1 & 1,1 & 100,0 \\
\hline Negativa & $\begin{array}{l}\text { A10 - Problemas com frações me fazem sentir como se estivesse } \\
\text { perdido (a) em uma selva de números e sem encontrar a saída. }\end{array}$ & 14,4 & 40,8 & 35,7 & 9,1 & 100,0 \\
\hline Positiva & A11 - "Frações" é um conteúdo que eu aprecio grandemente. & 20,8 & 60,5 & 16,5 & 2,1 & 100,0 \\
\hline Negativa & $\begin{array}{l}\text { A12 - Quando eu ouço a palavra Fração, eu tenho um sentimento de } \\
\text { aversão. }\end{array}$ & 9,6 & 42,1 & 42,4 & 5,9 & 100,0 \\
\hline Negativa & $\begin{array}{l}\text { A13 - Eu encaro problemas sobre frações com um sentimento de } \\
\text { indecisão, que é resultado do medo de não ser capaz de solucionar } \\
\text { problemas. }\end{array}$ & 8,8 & 37,1 & 46,7 & 7,5 & 100,0 \\
\hline Positiva & A14 - Eu gosto realmente de frações. & 26,4 & 55,7 & 15,5 & 2,4 & 100,0 \\
\hline Positiva & $\begin{array}{l}\text { A15 - "Frações" é um dos conteúdos que eu realmente gosto de } \\
\text { estudar na escola. }\end{array}$ & 25,7 & 59,4 & 12,6 & 2,4 & 100,0 \\
\hline
\end{tabular}

\footnotetext{
${ }^{9}$ CT (Concordo Totalmente), C (Concordo), D (Discordo) e DT (Discordo Totalmente)
} 
Negativa A16 - Pensar sobre a obrigação de resolver um problema com $6,1 \quad 40,5 \quad 46,1 \quad 7,2 \quad 100,0$ frações me deixa nervoso(a).

Negativa $\quad$ A17 - Eu nunca gostei de solucionar problemas sobre frações e esse $\quad 11,5 \quad 47,7 \quad 32,8 \quad 8,0 \quad 100,0$ é o conteúdo que me dá mais medo.

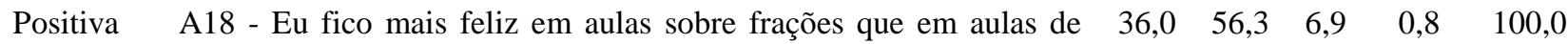
qualquer outro conteúdo.

Positiva A19 - Eu me sinto tranqüilo (a) quando soluciono problemas sobre $\quad 21,6 \quad 58,9 \quad 17,6 \quad 1,9 \quad 100,0$ frações e gosto muito desse conteúdo.

Positiva A20 - Eu tenho uma reação definitivamente positiva com relação a $\quad 21,1 \quad 61,6 \quad 15,2 \quad 2,1 \quad 100,0$ frações: Eu gosto e aprecio problemas com esse conteúdo.

O percentual de sujeitos que concordam com as proposições negativas varia de 60 a $40 \%$, de acordo com a figura 3. É possível observar que quase $60 \%$ dos estudantes concordam com o sentimento de medo e apenas 40\% concordam com a afirmação “'Dá um branco' na minha cabeça e não consigo pensar claramente quando resolvo problemas com frações".

Figura 3- Distribuição percentual dos sujeitos nas proposições negativas, ordenada de forma decrescente.

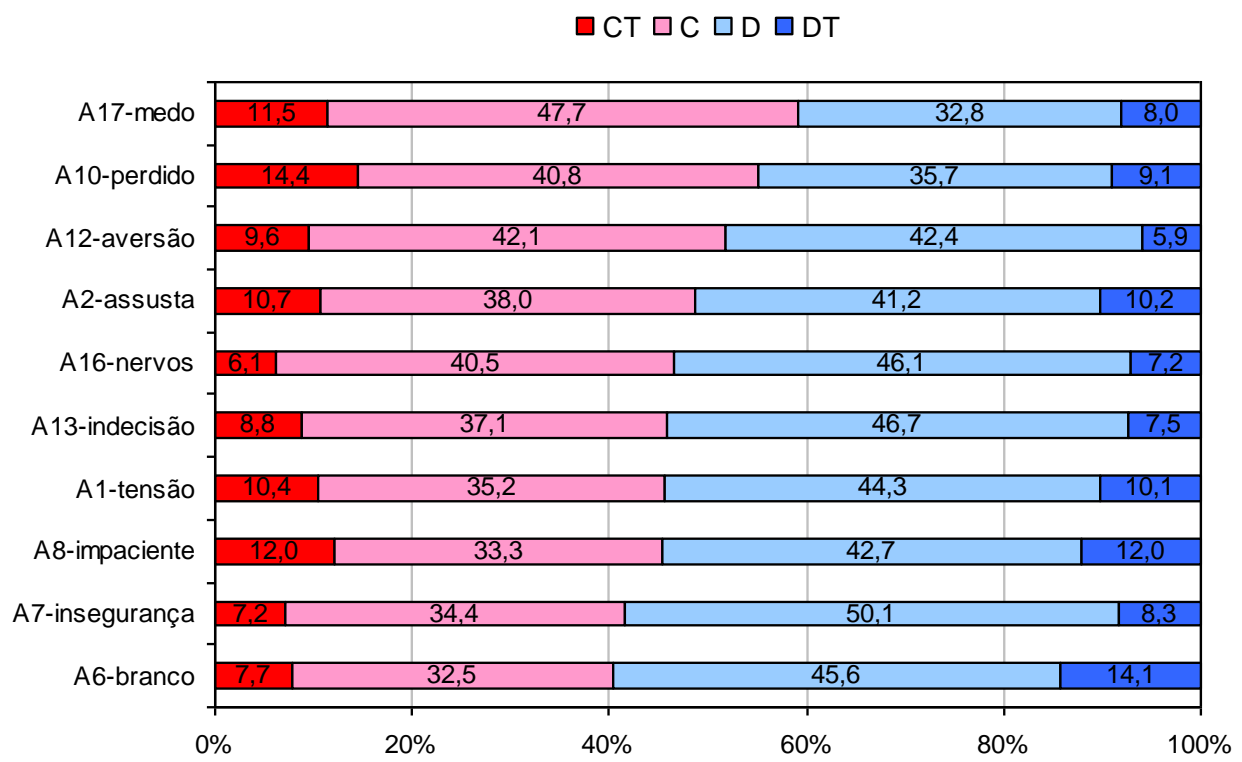

Fonte: Dados da pesquisa

A Figura 4 mostra que apenas um terço concorda que o tema frações é interessante e 30\% dos sujeitos afirmaram ter um sentimento bom. Nas outras proposições positivas, o percentual é inferior a um quinto dos participantes. 
Figura 4 - Distribuição percentual dos sujeitos nas proposições positivas, ordenada de forma decrescente.

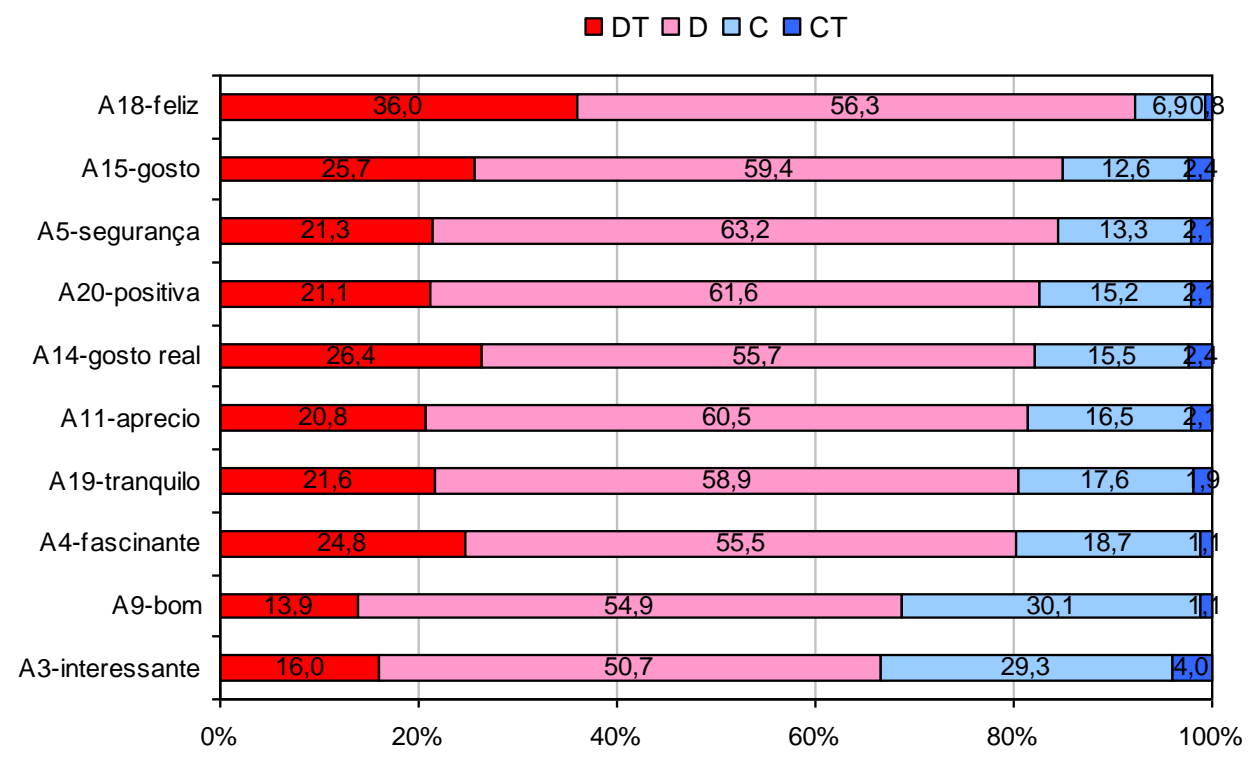

Fonte: Dados da pesquisa

A Figura 5 ilustra a distribuição da pontuação na escala, que tende a ser negativa. A pontuação média foi de 44,6, com desvio padrão de 10,5 pontos. Tomando como referência o ponto médio de 50, verifica-se que esse grupo mostra atitudes mais negativas do que positivas.

Figura 5- Distribuição da pontuação na escala de atitudes em relação à fração

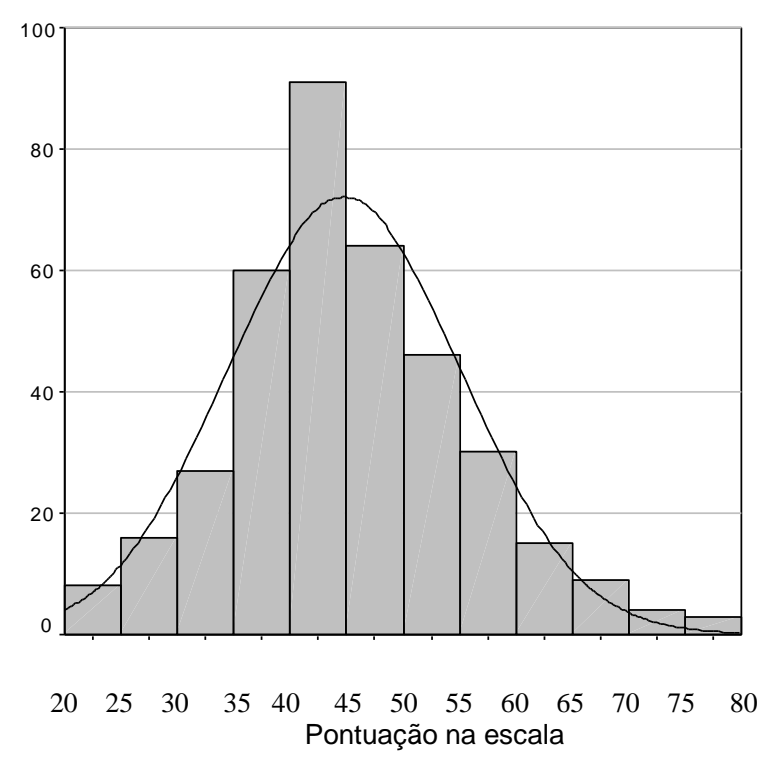




\section{Algumas Considerações}

A escala de atitudes apresentada pode ser considerada um instrumento válido para avaliar as atitudes dos alunos em relação a frações. A validação desta escala de atitudes em relação a frações apresentou um alfa de Cronbach, que mede a fidedignidade do instrumento, de 0,9443, considerado muito bom. Outras escalas de atitudes semelhantes a esta, como a de estatística, validada por Cazorla, Silva, Vendramini e Brito (1999), apresentou um alfa de Cronbach de 0,95, e a de Moron (1999) em relação à Matemática para professores, encontrou um valor de 0, 9498. Também a escala de atitudes em relação à Matemática adaptada e validada por Brito (1996) apresentou um coeficiente de credibilidade de $0,9494$.

Outras relações entre: atitudes, gênero e desempenho dos alunos do Ensino Médio que aprofundam o uso desta escala e que motivou este estudo, podem ser encontrados em Justulin (2009). Neste trabalho de Mestrado, através de uma análise estatística dos resultados, foi possível notar uma correlação entre a pontuação da escala de atitudes em relação à Matemática e a escala de atitudes em relação a Frações $(\mathrm{r}(94)=0,678 ; \mathrm{p}=0,000)$. Esse resultado aponta para que atitudes negativas em relação à Matemática podem interferir no aprendizado dos números racionais já que as atitudes em relação a frações também aparecem negativas, ou vice versa.

Com relação ao uso da escala de atitudes, esta pode fornecer informações relevantes ao pesquisador ou ao professor da disciplina a respeito das atitudes em relação à matemática do grupo avaliado. Considerando que as atitudes podem ser modificadas ao longo do tempo, as escalas são um importante recurso, um ponto de partida, para o desenvolvimento de atitudes positivas em sala de aula.

O uso das escalas, no entanto, deve considerar as limitações deste instrumento. O ideal seria a combinação, na medida do possível, das escalas de atitudes com outros instrumentos que, em conjunto, podem fornecer dados de natureza quanti e qualitativa a respeito das atitudes do grupo investigado.

\section{Agradecimento}

Gostaríamos de destacar a contribuição e participação na construção da escala de atitudes em relação a frações da $\operatorname{Prof}^{a}$ Dr $^{\mathrm{a}}$ Márcia Regina Ferreira de Brito Dias. Suas sugestões e 
presença na banca de defesa de dissertação de Mestrado da primeira autora foram fundamentais para a realização deste trabalho.

\section{Referências}

AIKEN, L. R. Attitudes toward mathematics. Review of educational research, Washington, v. 4, n. 40, p. 551-596, 1970.

AIKEN, L. R.; DREGER, R. M. Personality correlates of attitude toward Mathematics. Journal of educational research, Washington, v. 9, n. 56, p.476-480, 1963.

AIKEN, L. R.; DREGER, R. M. The effect of attitudes on Performance in Mathematica. Journal of Educational Psychology, Arlington, v. 52, n. 1, p. 19-24, 1961.

BRITO, M. R. F. Um estudo sobre as atitudes em relação à Matemática em estudantes de $\mathbf{1}^{\circ}$ e $2^{\circ}$ graus. Trabalho de Livre docência. 383 f. Faculdade de educação - Universidade Estadual de Campinas, Campinas, 1996.

. Adaptação e Validação de uma Escala de Atitudes em Relação à Matemática. Zetetiké, Campinas, CEMPEM, v. 6, n. 9, p. 109-162, jan/jun. 1998.

CAZORLA, I. M., SILVA, C. B.; VENDRAMINI, C. ; BRITO, M. R. F. de. Adaptação e validação de uma escala de atitudes em relação à estatística. In Conferência Internacional: experiências e perspectivas do ensino da estatística, 1, 1999. Florianópolis. Anais... Florianópolis: UFSC/ PRESTA/ IASE, p. 45-57, 1999.

JUSTULIN, A. M. Um estudo sobre as relações entre atitudes, gênero e desempenho de alunos do Ensino Médio em atividades envolvendo frações. 2009. 250p. Dissertação (Mestrado em Ensino de Ciências e Matemática) - Faculdade de Ciências, Universidade Estadual Paulista, Bauru.

KLAUSMEIER, H. J.; GOODWIN, W. Manual de psicologia educacional: Aprendizagem e Capacidades Humanas. Tradução: Maria Célia Teixeira Azevedo de Abreu. São Paulo: Harper \& Row do Brasil, 1977.

KRUTETSKII, V. A. The psychology of mathematical abilities in schoolchildren. Chicago: The University of Chicago Press, 1976.

MORON, C. F. Um estudo exploratório sobre as concepções e as atitudes dos professores de Educação Infantil em relação à Matemática. 1999. 133f. Dissertação (Mestrado em Educação) Universidade Estadual de Campinas, Campinas.

NORUSIS, M. J. SPSS for Windows Base System User's Guide Release 6.0. Chicago: SPSS Inc, 1993.

PEREIRA, J. C. R. Análise de dados qualitativos: estratégias metodológicas para as ciências de saúde, humanas e sociais. São Paulo: EDUSP, 1999. 
SARABIA, B. A aprendizagem e o ensino das atitudes. In: COLL, C. et al. Os conteúdos na reforma: ensino e aprendizagem de conceitos, procedimentos e atitudes. Tradução: Beatriz Affonso Neves. Porto Alegre: Artes Médicas, 1998.

SILVA, C. B. da. Atitudes em relação à Estatística: um estudo com alunos de graduação. 2000. 157 f. Dissertação (Mestrado em Educação) - Universidade Estadual de Campinas, Campinas.

\section{Anexo - ESCALA DE ATITUDES EM RELAÇÃO A FRAÇÕES ${ }^{10}$}

01- Eu fico sempre sob uma terrível tensão quando resolvo problemas que envolvem frações.

( ) Concordo Totalmente ( ) Concordo ( ) Discordo ( ) Discordo Totalmente

02- Eu não gosto de frações e me assusta ter que trabalhar esse conceito.

( ) Concordo Totalmente ( ) Concordo ( ) Discordo ( ) Discordo Totalmente

03- Eu acho "frações" muito interessante e gosto das aulas sobre isso.

( ) Concordo Totalmente ( ) Concordo ( ) Discordo ( ) Discordo Totalmente

04- Frações é um conceito fascinante e divertido.

( ) Concordo Totalmente ( ) Concordo ( ) Discordo ( ) Discordo Totalmente

05- Problemas com frações me fazem sentir seguro (a) e é, ao mesmo tempo, estimulante.

( ) Concordo Totalmente ( ) Concordo ( ) Discordo ( ) Discordo Totalmente

06- "Dá um branco" na minha cabeça e não consigo pensar claramente quando resolvo

problemas com frações.

( ) Concordo Totalmente ( ) Concordo ( ) Discordo ( ) Discordo Totalmente

07- Eu tenho sensação de insegurança quando me esforço para resolver problemas de frações.

( ) Concordo Totalmente ( ) Concordo ( ) Discordo ( ) Discordo Totalmente

08- Conteúdos com frações me deixam inquieto (a), descontente, irritado (a) e impaciente.

( ) Concordo Totalmente ( ) Concordo ( ) Discordo ( ) Discordo Totalmente

09- O sentimento que tenho com relação a Frações é bom.

( ) Concordo Totalmente ( ) Concordo ( ) Discordo ( ) Discordo Totalmente

10- Problemas com frações me fazem sentir como se estivesse perdido (a) em uma selva de números e sem encontrar a saída.

\footnotetext{
${ }^{10}$ Baseada na escala de atitudes em relação à matemática que foi elaborada e aprimorada por Aiken (1963), adaptada e validada por Brito (1996). Enfatiza as atitudes em relação a frações e a solução de problemas e não apenas o conceito de fração.
} 
( ) Concordo Totalmente ( ) Concordo ( ) Discordo ( ) Discordo Totalmente 11- "Frações" é um conteúdo que eu aprecio grandemente.

( ) Concordo Totalmente ( ) Concordo ( ) Discordo ( ) Discordo Totalmente 12- Quando eu ouço a palavra Fração, eu tenho um sentimento de aversão. ( ) Concordo Totalmente ( ) Concordo ( ) Discordo ( ) Discordo Totalmente 13- Eu encaro problemas sobre frações com um sentimento de indecisão, que é resultado do medo de não ser capaz de solucionar problemas.

( ) Concordo Totalmente ( ) Concordo ( ) Discordo ( ) Discordo Totalmente 14- Eu gosto realmente de frações.

( ) Concordo Totalmente ( ) Concordo ( ) Discordo ( ) Discordo Totalmente 15- "Frações" é um dos conteúdos que eu realmente gosto de estudar na escola.

( ) Concordo Totalmente ( ) Concordo ( ) Discordo ( ) Discordo Totalmente

16- Pensar sobre a obrigação de resolver um problema com frações me deixa nervoso(a).

( ) Concordo Totalmente ( ) Concordo ( ) Discordo ( ) Discordo Totalmente

17- Eu nunca gostei de solucionar problemas sobre frações e esse é o conteúdo que me dá mais medo.

( ) Concordo Totalmente ( ) Concordo ( ) Discordo ( ) Discordo Totalmente

18- Eu fico mais feliz em aulas sobre frações que em aulas de qualquer outro conteúdo.

( ) Concordo Totalmente ( ) Concordo ( ) Discordo ( ) Discordo Totalmente

19- Eu me sinto tranqüilo (a) quando soluciono problemas sobre frações e gosto muito desse conteúdo.

( ) Concordo Totalmente ( ) Concordo ( ) Discordo ( ) Discordo Totalmente

20- Eu tenho uma reação definitivamente positiva com relação à frações: Eu gosto e aprecio problemas com esse conteúdo.

( ) Concordo Totalmente ( ) Concordo ( ) Discordo ( ) Discordo Totalmente

21- Não tenho um bom desempenho para solucionar problemas sobre frações.

( ) Concordo Totalmente ( ) Concordo ( ) Discordo ( ) Discordo Totalmente

Anote a seguir qualquer dúvida ou observação que queira fazer com relação a essa escala.

Recebido em janeiro de 2013

Aprovado em março de 2014 